\title{
Referencias formativas do Grupo de Estudos Práticas Educativas em Movimento
}

\author{
Maria Carmem Freire Diógenes Rêgo \\ Marta Maria Castanho Almeida Pernambuco (In Memoriam)' \\ Universidade Federal do Rio Grande do Norte (Brasil)
}

\section{Resumo}

Grupo de Estudos de Práticas Educativas em Movimento (GEPEM), da Universidade Federal do Rio Grande do Norte, coordenado pela professora Marta Maria Castanho Almeida Pernambuco (1994-20 18), desenvolveu ações formativas para a formação de professores nos Estados do Rio Grande do Norte, de São Paulo e do Rio de Janeiro. O presente trabalho analisa as práticas escolares resultantes das referidas ações formativas em conformidade com o pensamento e a práxis pedagógica sistematizada por Paulo Freire. Em termos de conclusão, o estudo identificou os princípios que orientam as ações formativas do GEPEM: o sujeito como ser histórico-social faz parte de uma determinada comunidade; o conhecimento é construído nas relações sociais; e a realidade local é geradora de conteúdo. Ademais, considera a perspectiva freiriana de dialogicidade e de construção coletiva a partir da ação-reflexão-ação e do processo de conscientização. Palavras-chave: Pensamento e práxis de Paulo Freire. Formação de professores. Ações formativas.

\section{Formative references of the Group of Studies on Educational Practices in Movement}

\begin{abstract}
The Group of Studies on Educational Practices in Movement (GEPEM), of the Rio Grande do Norte Federal University, coordinated by the professor Marta Maria Castanho Almeida Pernambuco (1994-20 18), developed formative actions for the teacher training in the Statesof Rio Grande do Norte, São Paulo and Rio de Janeiro. The present work analyzes scholar practices as a result from the mentioned formative actions in accordance with the thought and pedagogical praxis systematized by Paulo Freire. To conclude, the study identified the principles that guide GEPEM's training actions: the person as a historical-social being is part of a community; knowledge is built in social relations; and local reality is content-generating. Furthermore, it considers Freirianperspective of dialogicity and collective construction based on action-reflection-action and the process of awareness.
\end{abstract}

Keywords: Thought and praxis of Paulo Freire. Teacher training. Formative actions. 


\section{Referencias formativas del Grupo de EstudiosPrácticas Educativas en Movimiento}

\section{Resumen}

El Grupo de Estudios de Prácticas Educativas enMovimiento (GEPEM), de la Universidade Federal do Rio Grande do Norte, coordinado por laprofesora Marta Maria Castanho Almeida Pernambuco (1994-20 18), desarrollóacciones formativas para laformación de profesoresenlos estados de Rio Grande do Norte, de São Paulo y Rio de Janeiro. El presente trabajo analiza las prácticas escolares resultantes de las referidas acciones formativas en conformidad con el pensamiento y la praxis pedagógica sistematizada por Paulo Freire. En términos de conclusión, el estudio identificó los principios que orientan las acciones formativas del GEPEM, con los siguientes presupuestos: el sujeto como ser histórico-social forma parte de una determinada comunidad; el conocimiento se construye en las relaciones sociales; y la realidad local es generadora de contenido. Además, considera la perspectiva freireana de dialogicidad y de construcción colectiva a partir de la acción-reflexión-acción y del proceso de concientización. Palabras clave: Pensamiento y praxis de Paulo Freire. Formación de profesores. Acciones formativas.

\section{Introdução}

ser humano aprende a ser humano aprendendo as significações que os outros dão à vida, à terra, ao amor, à opressão e à libertação (FREIRE, 2007).

O Grupo de Práticas Educativas em Movimento (GEPEM) historicamente tem atuado tanto nos movimentos de reorientação curricular, na assessoria de políticas educacionais e gestões administrativas, em propostas educativas que se propõem à mudança nas sistematizações das pesquisas que vem realizando sobre práticas educativas e sociais, considerando que a formação de professores se dá permanentemente tendo como foco a escola. O GEPEM é um Grupo de Pesquisa que foi criado em 1994, pela professora Marta Maria Castanho Almeida Pernambuco, vinculado ao Núcleo de Estudos e Pesquisa em Educação, Ciência e Tecnologia - NEPECT/PPGEd/UFRN, com área de concentração em ciências humanas e educação. Desde sua criação vem desenvolvendo projetos, que proporcionam um espaço de articulação nas três dimensões da universidade, a saber: ensino-extensão-pesquisa, bem como na formação de professores e pesquisadores. 
Desde então, uma questão sempre inquietou o grupo: como sistematizar essas contribuições de forma que possam ser generalizadas para outras realidades?

Tal proposta caracteriza a forma de construir conhecimento de um grupo de pesquisa, tanto nas reflexões teóricas quanto nas intervenções. Para Delizoicov (2004), uma das características da produção é de ser elaborada de forma compartilhada por pesquisadores, estando agregados em torno de alguns elementos. Nesse sentido, tenta-se explicitar o "pensamento coletivo" que os integrantes do GEPEM vêm construindo a partir de suas atuações em processos educativos e nas pesquisas.

Segundo Delizoicov (2004) e LudwikFleck (1896) esse "pensamento coletivo" apresenta uma vasta produção sobre epistemologia, podendo ser considerado pioneiro na abordagem construtivista e sociologicamente orientada sobre História e Filosofia da Ciência. Nas palavras do próprio Delizoicov:

Fleck, nas suas considerações epistemológicas que faz, argumenta sobre o papel dos distintos coletivos de pensamento [...] ao analisar a produção e a disseminação de conhecimentos. Ele caracteriza um coletivo de pensamento como constituído por um coletivo de indivíduos que é portador de um estilo de pensamento, o qual pode compreender sinteticamente como sendo caracterizado por conhecimentos e práticas compartilhadas. [...]. Para ele o sujeito do conhecimento estabelece interações com o objeto do conhecimento através de relações que são mediatizadas pelo que ele denominou estilo de pensamento (DELIZOICOV, 2004, p. 164, grifo do autor).

Ao propor o seu modelo epistemológico, Fleck tem a intenção de propor uma teoria do conhecimento que não se ocupe apenas da produção da ciência, afirmando que:

A fertilidade da teoria do pensamento coletivo se mostra precisamente na possibilidade que nos proporciona para comparar e investigar de forma uniforme o pensar primitivo, arcaico, ingênuo $[\ldots]$, também pode ser aplicado ao pensamento de um povo, de uma classe ou de um grupo [...] (FLECK, 1986, p.96).

Dessa forma, a pesquisa caracterizou um coletivo de pensamento que foi sendo constituído por um grupo de indivíduos que adotou um estilo de pensamento ao longo de sua trajetória histórica de produção, de conhecimentos 
e de práticas compartilhadas nas pesquisas e nas atuações em escolas e em movimentos sociais. Na identificação dos princípios que fundamentam esse Grupo, aparecerem recorrentemente nos diferentes documentos analisados, tais como: teses de doutorado, livros publicados, material de apoio para professores e alunos etc., os quais são constitutivos das práticas, parametrizando as tomadas de decisão. Vale ressaltar que esses princípios são indissociáveis, ou seja, não é possível separá-los na prática, embora, para mais bem os definir, seja conveniente procurar tratá-los separadamente, mesmo correndo o risco de ser repetitivo em alguns momentos. Nessa perspectiva, discutimos os referenciais que fundamentam os fatores presentes nas práticas formativas de professores orientados pelo GEPEM.

Os princípios do GEPEM também são balizadores para todas as suas ações, seja para a formação de professores e reorientação do projeto da escola, seja para as ações de pesquisa com grupos sociais organizados: movimento de mulheres, dos trabalhadores do campo, entre outros. Nesse processo, consideramos que toda prática depende de uma visão de mundo dos sujeitos que atuam nela, ou seja, as práticas educativas sempre trazem uma opção teórica, considerando que nem sempre essa opção é consciente 4 e coerente, iá que muitas vezes se assumem posturas que são aprendidas com os outros - familiares, professores, colegas - ao longo da vida, as quais se "misturam" com as novas concepções, porque é difícil romper com velhos comportamentos, aprendizagens que já foram incorporadas no cotidiano. Essa opção é explicitada na definição de princípios, organizadores, parâmetros e critérios de escolha que embasam as tomadas de decisões no seu processo de construção.

A opção teórica torna-se intencional-consciente, no momento em que se conseguem formular propostas de ação orientadas pela concepção à qual se filia e isso não acontece naturalmente com todas as ações cotidianas. Os integrantes do GEPEM sempre tiveram a preocupação-intencionalidade de extrair referências, tentando sistematizar sínteses durante toda sua trajetória de construção coletiva, posto que, também, estão vinculados a um grupo de pesquisa.

Os princípios identificados e que orientam as ações do GEPEM nas práticas formativas fundamentadas, principalmente, nas ideias de Paulo Freire, podem ser sintetizados nos seguintes: 
- $\bigcirc$ sujeito como ser histórico-social faz parte de uma determinada comunidade;

- $O$ conhecimento é construído nas relações sociais e a realidade local é geradora de conteúdo;

- As relações são estabelecidas mediante os processos de dialogicidade, construção coletiva e processo de conscientização.

Revendo as obras de Paulo Freire, consideramos que só é possível haver reflexão sobre a ação, com os outros, num processo de construção coletiva, no qual o sujeito (individual) é produtor de seu conhecimento e de sua história, e o conhecimento é construído nas relações sociais (na construção coletiva), entendendo a realidade local como geradora de conteúdo, de conhecimento.

\section{O sujeito como ser histórico-social e parte de uma determinada comunidade}

Paulo Freire (1988) defende a ideia de sujeito da práxis, posto que se humaniza e se constrói no tempo histórico e em determinado espaço social. Para ele, a realidade social objetiva é produto da ação dos homens e, assim como ela não existe por acaso, também não se transforma por acaso. Nesse sentido, transformar a realidade"[...] é tarefa histórica, é tarefa dos homens" (FREIRE, 1988, p. 39). A esse respeito, Paulo Freire afirma que:

Comecemos por afirmar que somente o homem, como um ser que trabalha, que tem um pensamento-linguagem, que atua e é capaz de refletir sobre si mesmo e sobre a sua própria atividade, que dele se separa, somente ele, ao alcançar tais níveis, se fez um ser da práxis. Somente ele vem sendo um ser de relações num mundo de relações. [...] Desprendendo-se do seu contorno, veio tornando-se um ser, não da adaptação, mas da transformação do contorno, um ser de decisão [...] (FREIRE, 1992, p. 39).

sujeito torna-se/faz-se humano pelo agir, agir que é simultaneamente histórico e social (SEVERINO, 1995). Considerar o professor como sujeito histórico-social significa pensar quem é esse professor, em que prática e realidade está inserido, quais as necessidades e possibilidades desse professor, considerando que a nossa humanidade está reconhecida pelas diferenças dos nossos modos de ser, pensar e agir, diferenciando-se das condições biológicas 
que são comuns aos outros seres vivos. Freire chama a atenção para o processo de humanização/hominização do homem em toda a sua obra:

Tenho chamado a atenção para a natureza humana construindo-se social e historicamente e não como um a priori. A trajetória pela qual nos fazemos conscientes está m arcada pela finitude, pela inconclusão e nos caracteriza como seres históricos (FREIRE, 1996, p. 75).

Esse princípio tem fundamentado todas as tomadas de decisões a respeito dos professores. Considerar o professor como sujeito histórico-social pressupõe reconhecê-lo como capaz de refletir sobre suas ações, capaz de replanejar, pensar, agir, ou seja, de fazer e refazer a sua prática cotidiana. Nas práticas formativas analisadas, a prática que o professor já desenvolve é o ponto de partida, mas ele é o sujeito dessa prática e é ele que precisa analisá-la, desvendá-la para transformá-la. Sem essa atuação do professor, não acredito que haja transformação da prática. Não é um grupo de pesquisadores/formadores "iluminados" que vai transformar a prática dele. "A não ser que se pretenda fazer para eles a transformação e não com eles - somente como nos parece verdadeira esta transformação" (FREIRE, 1988, p. 54, grifo do autor).

Em todas as atuações do GEPEM, o professor é o sujeito de sua prática e, portanto, ele participa ativamente do seu processo de formação. Nas práticas analisadas, os professores atuavam em todos os momentos: no levantamento preliminar da realidade local, na análise dos dados coletados, no planejamento da programação curricular, no planejamento das aulas para os alunos, fazendo e refazendo o caminho que seria percorrido com o aluno, participando das análises dos resultados das pesquisas, inclusive apresentando os resultados dessas práticas em diferentes locais (congressos, encontros entre professores etc.).

Nas ações desenvolvidas pelo GEPEM, a escola onde o professor atua é o espaço de construção e produção de conhecimento dele(a). Na análise das práticas, esse princípio orienta a elaboração de todas as ações dos professores.

Segundo Delizoicov, Castilho, Cutolo, Ros e Lima (2002), considerar o professor como sujeito da sua história significa instrumentá-lo para atuar sobre sua prática, envolvendo-o em todos os momentos dessa formação, reconhecendo-o como sujeito de sua prática. Por sua vez, na ótica de Paulo 
Freire (1996, p. 22), é indispensável que desde o início de sua experiência formadora o docente assuma-se como sujeito também da produção do saber, convencendo-se "[...] definitivamente de que ensinar não é transferir conhecimento, mas criar as possibilidades para a sua produção ou a sua construção". Portanto, considerar o docente como sujeito do conhecimento significa, também, considerá-lo capaz de construir a programação da escola e não a receber pronta de uma equipe de especialistas da secretaria de educação.

Para considerar o sujeito como ser histórico-social, é necessário um esforço conjunto das equipes da escola na construção da programação de um ano letivo. Os professores participam ativamente de todos os momentos, inclusive na estratégia de inclusão na construção de novos sujeitos que entram ao longo do percurso. Incluir os novos sujeitos significa retomar o processo já construído e incorporar a forma de pensar e atuar desses docentes, assim, eles também se sentirão sujeitos dessa prática, sendo capazes de atuar e recriar. Nesse sentido, é importante que os docentes cheguem como sujeitos atuantes e não como objetos que precisam ser encaixados. Dessa forma, é necessário planejar, intencionalmente, estratégias que incluam todos no processo de construção, garantindo a elaboração coletiva da programação da escola, não sendo, portanto, a prefixação de um programa para ser cumprido, tampouco cair num espontaneísmo que aproveita a interação do momento.

Nesse processo, o diálogo surge como necessidade para a elaboração do programa com os educadores que opinam, problematizam, discordam, sentindo-se produtores e participantes do programa. Os educadores são envolvidos em todos os momentos da programação, desde a análise dos dados da realidade até a produção das atividades de sala de aula. Nessa construção, os educadores desvelam tanto a realidade em que estão trabalhando quanto a sua própria prática. Ao olhar a prática a distância e, ao mesmo tempo, ao problematizá-la, é criada a necessidade de transformar essa realidade, de construir algo novo. Para transformar essa realidade, faz-se necessário, num primeiro momento, desvelá-la, pois ao desvelá-la os sujeitos comprometem-se na práxis com a sua transformação, para, num segundo momento, em que a realidade já foi transformada, deixa de ser dos outros e passa a ser de todos, dos sujeitos que participaram da transformação, num processo de permanente transformação (FREIRE, 1988).

Como afirma Pernambuco (1993, p. 21), a inclusão dos sujeitos numa construção coletiva pode ser trabalhosa, mas também é recompensadora, pois, 
"como um processo dinâmico, precisa ser continuamente repensado e, como um processo coletivo, reformulado com os nossos parceiros na caminhada". É preciso, portanto, respeitar a diversidade da formação dos docentes, tentando identificar o que é necessidade e o que é significativo para o grupo, percebendo dificuldades, limites e avanços.

É igualmente importante a construção conjunta dos materiais/ estratégias/ instrumentos que serão utilizados nas aulas, considerando, dessa forma, o professor como produtor do seu trabalho. Nessa perspectiva, Pernambuco acrescenta que:

Dentro da compreensão de processo que fundamenta esta proposta, entende-se que a criação de novos instrumentos e a busca de fundamentação são parte integrante e permanente, tanto da atividade dos educadores - e de certa forma pesquisadores - que está sendo desenvolvida na escola, quanto da de outros pesquisadores que a assessoram. Dentro de um quadro de referências e alternativas de materiais didáticos, cabe aos professores, que também são produtores de referências e materiais, tomarem as decisões e organizarem as atividades de sua sala de aula (PERNAMBUCO, 1994, p. 79).

Revendo as ideias de Paulo Freire em Pedagogia do Oprimido (1988), é possível considerar que os homens, nos vários momentos de sua ação e/ou transformação, precisam reconhecer-se como homens, na sua vocação ontológica e histórica do ser mais. "A reflexão e a ação se impõem, quando não se pretende, erroneamente, dicotomizar o conteúdo da forma histórica de ser homem."(FREIRE, 1988, p. 59).

\section{O conhecimento é construído nas relações sociais e a realidade local é geradora de conteúdo}

Para os integrantes do GEPEM, a realidade dos sujeitos também é geradora de conteúdos, constituindo o ponto de partida e o ponto de chegada. Esse princípio perpassa todas as ações educacionais do GEPEM, ou seja, ocorre nas situações escolares para alunos, nas situações de aprendizagens não formais, nas situações educacionais com movimentos sociais e nas situações formativas de professores. Pernambuco considera que: 
Conhecer é apreender o mundo em suas relações, um processo necessariamente dinâmico, no qual, através de ações físicas e mentais, os diferentes sujeitos constroem, em uma interação coletiva, novas formas de se relacionar e compreender o mundo (PERNAMBUCO, 1993, p. 24).

Ademais, a utilização de temas geradores para a construção de programações escolares tem sido a forma de sistematizar os conhecimentos da realidade local, como ponto de partida para a seleção dos conteúdos. A esse respeito, Paulo Freire (1988, p. 83-84) defende a utilização de temas geradores, como forma de "[...] devolver ao povo os elementos que forneceram aos educadores-educandos de forma organizada, sistematizada e acrescentada".

Considerar que o conhecimento é construído nas relações sociais significa dizer que ele é construído coletivamente. Desde muito cedo, os sujeitos aprendem com o grupo social do qual fazem parte, tanto regras sociais como valores, crenças, atitudes, linguagens e explicações, evoluindo, ao longo de sua vida, em consequência de seu crescimento orgânico e do tipo de relações que estabelecem.

Em muitas cidades no interior do Rio Grande do Norte, existem pessoas que nunca foram à escola e que utilizam, cotidianamente, alguns conhecimentos aprendidos nas vivências com outros mais experientes, que são passados de geração em geração, como as parteiras e as pessoas que usam remédios caseiros tipo chás e "garrafadas".

Na sociedade ocidental, o conhecimento sistematizado ou da ciência tem um conjunto de pressupostos de organização e construção com características e especificidades próprias. Para Pernambuco e Paiva (2005), as ciências naturais, humanas, a matemática e a filosofia têm alguns pontos comuns: coerência interna nas explicações; interpretações construídas a partir da delimitação do objeto investigado; definição do seu domínio de validade, referendado por outros cientistas e/ou filósofos, por meio de registros escritos e processos explícitos de ensino.

Também é sabido que o conhecimento sistematizado tem origem no enfrentamento de problemas e situações que a sociedade ocidental necessitou resolver no passado ou contemporaneamente. Pernambuco e Paiva (2005) consideram que os seus resultados influenciam o cotidiano dos sujeitos, ou seja, na forma como o trabalho se organiza, o que é disponibilizado para se comprar, como tratar do corpo etc. Argumentam ainda que: "Se queremos intervir na 
maneira como a vida se organiza, participar da construção da sociedade e da natureza em que vivemos, precisamos saber o que já foi acumulado como conhecimento sistematizado" (PERNAMBUCO; PAIVA, 2005, p. 10).

A relação entre os conhecimentos sistematizados e os do cotidiano tem sido trabalhada por diversos autores e em diferentes perspectivas, embora, uma questão já seja consensual: os dois tipos de conhecimentos são o sujeito vive ou do contexto macrossocial. Os importantes para serem considerados pelas práticas educativas, seja para alunos, seja para docentes. Os conhecimentos do cotidiano podem ser originados do local onde conhecimentos locais são construídos pelos sujeitos em suas vivências cotidianas no grupo social do qual fazem parte, ou da realidade micro; os conhecimentos globais são oriundos das vivências e do acesso às informações do contexto social ou da realidade macro.

No mundo contemporâneo, em função do acesso aos meios de comunicação, o cotidiano dos sujeitos está impregnado de informações diversas e explicações diferentes para o que acontece no entorno. Essas construções conduzem as ações dos sujeitos sobre o mundo (DELIZOICOV; ANGOTTI; PERNAMBUCO, 2002). Portanto, existe uma relação dinâmica entre esses dois 10 tipos de conhecimentos, um retroalimentando o outro, tanto nas ações dos indivíduos como na organização da sociedade contemporânea. Compreender o cotidiano de quem aprende a cultura em que está imerso, sua visão de mundo, os meios de comunicação a que tem acesso é fundamental para propiciar a transição desses dois tipos de conhecimentos.

Nos processos de formação docente do GEPEM, a problematização da prática do professor, do que este já faz e sabe, é desencadeadora não só para a reorientação do currículo, mas também como parte fundamental de sua própria formação. Começar a partir da realidade, do contexto, dos interesses dos alunos tornou-se um jargão repetido por todos na área da educação, mas, na prática, não tem sido trivial transformar os conhecimentos do cotidiano como ponto de partida para introdução de novos conteúdos em sala de aula.

A esse respeito, Silva (1999) afirma que selecionar os conteúdos a partir dos problemas da realidade local não é um processo simples, pois mesmo os professores tendo participado de todo o processo (pesquisa e redução temática), continuam a selecioná-los de livros didáticos. Nesse caso, ainda persistem visões e atividades genéricas e o estudo sobre a problemática da realidade serve apenas como ilustração do conteúdo. Esse autor constata ainda alguns 
equívocos muito comuns nesse processo, como, por exemplo: os professores tendem a considerar apenas a sua própria visão da realidade; é difícil construir um entendimento da visão de mundo da comunidade a partir das falas selecionadas; a análise reducionista feita pela equipe sobre a problemática da realidade local não possibilita uma aquisição significativa - operacionalizada nas ações dos alunos -, restringindo-se à transmissão de conteúdos estanques e atitudes ideais, sem considerar as vivências da comunidade com o tema gerador escolhido.

Na opinião do mesmo autor, a seleção de conteúdos não pode se restringir a cortes fragmentados de objetos de estudo; antes, deve-se realizar uma análise relacional e contextualizada na micro e na macroestrutura social. Sob essa ótica, Silva (1999, p. 60) afirma que: "A análise relacional e sistêmica da realidade local a partir de suas contradições exige sucessivas aproximações e contextualizações metodológicas que a construção de uma rede temática procura organizar".

Também é preciso considerar que os conhecimentos e/ou as concepções construídos/adquiridos no cotidiano pelos professores, às vezes, interferem na forma de "ensinar" e "aprender" alguns conteúdos. Muitas vezes, os professores, culturalmente, acreditam em determinadas crenças, o que os leva a perpetuar essas crenças com seus alunos. A esse respeito, destacamos um caso curioso num curso que ministramos numa pequena cidade do interior do Rio Grande do Norte para professoras de educação infantil. Nessa cidadezinha, a população acreditava que os ratos, à noite, transformavam-se em morcegos. Mesmo depois de terem estudado sobre os dois animais, alguns professores continuaram argumentando que lá, na cidade deles, isso ocorria.

Além disso, é sabido que os professores constroem, nas suas vivências anteriores como alunos, um senso comum pedagógico sobre a aprendizagem dos indivíduos. É preciso considerar essas visões, construídas no cotidiano, nos processos de formação docente, posto que elas interferem diretamente na prática pedagógica. Da mesma forma que é preciso considerar o que os alunos já sabem sobre os conteúdos que se pretende 'ensinar' (PERNAMBUCO, 1993, p. 1221.

Segundo Pernambuco (1993), os alunos já têm muitas informações sobre o assunto a ser estudado, eles trazem para a sala de aula não só informações como ainda concepções e explicações, às vezes, tão consolidadas 
que entram em conflito com o conhecimento a ser apreendido. Também não é fácil nem trivial conseguir uma construção com os alunos, atendendo a todas as situações que surgem, tais como: os questionamentos inesperados, a tarefa de conciliar a ansiedade dos alunos, de ouvir e aproveitar as contribuições relevantes e, ao mesmo tempo, aproveitar aquelas que estão fora do assunto, mas que são importantes para os alunos que a levantaram. Enfim, a tarefa de manter um clima de construção coletiva, conquistando um ambiente de amizade e confiança.

Nesse processo, é possível, a partir do que os alunos já sabem, da problematização de suas falas, proposta pelo professor ou pelos colegas, buscar formas de interagir e aprender conjuntamente. Torna-se, assim, fundamental a construção conjunta de uma programação para um ano letivo da escola, envolvendo todos os segmentos escolares: professores, direção e coordenação pedagógica. Segundo Pernambuco:

Ao criar as condições para o próprio conhecimento ser adquirido de forma ativa, sendo principalmente as informações o suporte necessário para a composição de seus padrões e formas de padrões, podemos entendê-lo como socialmente construído, e, portanto, em modificação permanente (PERNAMBUCO, 1993, p. 25).

conhecimento é construído nas relações sociais que os sujeitos estabelecem e, portanto, a realidade local é geradora de conteúdos para os processos de programações escolares.

\section{Dialogicidade, construção coletiva e o processo de conscientização}

Considerando que diálogo, construção coletiva e conscientização são indissociáveis, identificamos esses três conceitos como sendo um princípio balizador para todas as ações desencadeadas pelo Grupo e fundamentadas, principalmente, nas ideias de Paulo Freire. $O$ pressuposto é que o processo de conscientização é efetivado por meio da dialogicidade e da construção coletiva, sendo difícil falar de uma sem considerar as demais.

Em relação ao diálogo, na perspectiva de Freire, este é considerado um fenômeno essencialmente humano constituído de duas dimensões indissociáveis e radicalmente e dependentes: a ação e a reflexão. A interação entre 
elas é fundamental para a efetivação do diálogo, de tal forma que sacrificada uma, mesmo que parcialmente, a outra fica prejudicada. Não há palavra verdadeira que não seja práxis. Sob essa ótica, pode-se dizer que a palavra verdadeira seja transformar o mundo (FREIRE, 1988, p. 77).

A palavra isolada da ação se transforma em palavreiro, verbalismo, blá-blá-blá. Do mesmo modo, se for exclusivizar a ação sem a reflexão, ela se transforma em ativismo. Nesse sentido, a ação pela ação, negando a reflexão, nega também a práxis verdadeira e impossibilita o diálogo (FREIRE, 1988). Diálogo que é estabelecido entre os homens para compreender e transformar o mundo.

Para Paulo Freire (1988), o diálogo sobre o mundo, necessariamente, tem de ser significativo para os sujeitos envolvidos. Diálogo no sentido mesmo de troca-troca de visões, de saberes, de concepções, o que implica uma atitude de respeito sobre o que o outro sabe, compreende e pensa. Nesse sentido, o diálogo é o encontro dos homens, mediatizados pelo mundo, para pronunciá-lo, não se esgotando, portanto, na relação pessoal eu-tu. Nas palavras de Freire:

Mas, se dizer a palavra verdadeira, que é trabalho, que é práxis, é transformar o mundo, dizer a palavra não é privilégio de alguns homens, mas direito de todos os homens. Precisamente por isso, ninguém pode dizer a palavra verdadeira sozinho, ou dizêlla para os outros, num ato de prescrição, com o qual rouba a palavra dos demais (FREIRE, 1988, p. 78).

Essa troca se estabelece na ação que realizam, no projeto que constroem coletivamente e tem um devir que aponta para a frente, para a possibilidade de mudança de consciência. $\bigcirc$ diálogo verdadeiro propicia a mudança de consciência, implicando uma mudança na ação do sujeito. Sob essa ótica, mudar não significa simplesmente mudar uma visão, um conceito isolado, mas mudar a forma de trabalhar com o conjunto de informações, conseguindo extrair o que é relevante, o que é fundamental para os sujeitos. Nesse sentido, conscientizar é criar elementos-mecanismos gerais de interpretação e ação sobre o mundo.

Na formação do educador, é preciso estabelecer um diálogo sobre a prática do professor, do seu cotidiano, do seu contexto, assim como dos seus saberes, e "[...] não é no silêncio que os homens se fazem, mas na palavra, no trabalho, na ação-reflexão" (FREIRE, 1988, p. 78). Esse diálogo funciona como 
propulsor das mediações que se estabelecem entre os sujeitos envolvidos na relação pedagógica.

Segundo Freire (1988), o diálogo na formação do educador não pode começar a ser estabelecido apenas na relação pedagógica de um curso para professores, deve começar muito antes, quando nos perguntamos em torno do que vamos dialogar com os educadores. Nesse sentido, "[...] esta inquietação em torno do diálogo é a inquietação em torno do conteúdo programático [...]" (FREIRE, 1988, p. 83).

Para Paulo Freire (1998), a experiência existencial do educando, nesse caso, o professor, é o ponto de partida para o estabelecimento de uma formação dialógica, considerando-o inserido num determinado contexto de vida, que pode ser conhecido e modificado. Se é inerente à dialogicidade, o dialogar com alguém sobre alguma coisa, na formação do educador, é condição sine qua non que se parta do que é familiar ao próprio educador(a), ou seja, a sua ação na sala de aula e na escola. Só assim ele participará efetivamente do diálogo (DELIZOICOV, 1982).

Nesse sentido, a utilização do diálogo para a transformação da ação dos educadores(as) precisa propiciar:

14 - Construção coletiva do projeto político pedagógico da escola, com ampla participação nas decisões e ações do currículo e da gestão escolar;

- Articulação teoria-prática, traduzindo um constante agir-refletir-agir dos educadores e demais sujeitos envolvidos na escola;

- Formação permanente dos educadores, partindo sempre da reflexão sobre a própria prática da escola e da sala de aula.

A formação deve ser realizada com o professor a partir da reflexão da sua própria prática, e não para o professor ou sobre o professor. Isso implica considerá-lo como sujeito da ação educativa, como sujeito do conhecimento. Nesse sentido, a sua participação no processo de formação deve se dar em todas as dimensões e em todos os momentos.

Pernambuco (1993, p. 23-24) analisa a relação dialógica que se estabeleceu na experiência afirmando: "O diálogo, a interlocução sobre um mundo, uma realidade partilhada, embora vista sob diferentes ângulos, é o principal motor, o que desencadeia e mantém o movimento do grupo". Nesse processo, ela afirma que se deve considerar o respeito pela fala de cada um, 
a assimetria de posições, estabelecendo comunicação a fim de que não vire um monólogo.

Nas diferentes propostas de trabalho realizadas a partir dos princípios do GEPEM, o diálogo estabelecido foi/é mediatizado pela própria realidade local e pelo contexto de atuação docente, respeitando as diferentes visões, assim como os diferentes níveis de conhecimento dos sujeitos envolvidos no processo, uma vez que a diversidade é considerada como fator positivo para a construção da prática. A partir da investigação temática, iniciava-se um diálogo entre os atores: equipe da universidade, docentes, discentes e comunidade, realizado por meio de questionários e entrevistas, reuniões e conversas informais com moradores, professores e alunos.

No processo de formação de professores, é condição necessária levá-los a refletir sobre o que pensam, o que sabem, o que fazem e como atuam na realidade, tomando consciência de suas visões de mundo, de infância, de aprendizagem, entre outros. Nessa perspectiva, a codificação, a descodificação e a problematização surgem como procedimentos metodológicos fundamentais para a mediação entre o contexto concreto e o teórico.

Tomando a prática como ponto de partida para a formação, revelam-se tensões, conflitos, intenções e contradições que são replanejados de forma coletiva. Nesse sentido, o próprio processo de construção coletiva da programação curricular já se constitui uma formação do(a) professor(a). Assim, é necessário possibilitar uma experiência de distanciamento, de modo que formadores e educadores possam refletir juntos, de forma dialógica e crítica, acerca do objeto que os mediatiza. A finalidade da decodificação é alcançar um nível crítico de conhecimento da realidade, iniciando pela própria experiência que o professor tem de sua situação em seu contexto real.

O distanciamento da realidade tem o objetivo de levar o professor a um processo de conscientização, ou à passagem de uma consciência ingênua para uma consciência crítica da realidade. Para Freire (1980, p. 29), conscientização é "[...] tomar posse da realidade [...]. A conscientização produz a desmitologização".

O sentido da educação continua sendo compreendido como "[...] um ato de intervenção no mundo" (FREIRE, 1996, p. 122). Nesse caso, a conscientização é entendida como um processo permanente de construção da criticidade. 
Na perspectiva freiriana, no processo de conscientização do educador, o ponto de partida seria o próprio educador com sua maneira de captar e de compreender a realidade, que, num primeiro momento, caracteriza-se por uma apreensão e captação de tipo especialmente mágico ou sincrético do real. Dessa forma, "[...] do mesmo modo que toda compreensão de algo corresponde, cedo ou tarde, uma ação, a uma compreensão primordialmente mágica corresponde uma ação também mágica" (FREIRE, 1980, p. 52).

Para concretizar o diálogo e a conscientização na formação do educador, o ponto de partida, necessariamente, é o próprio educador, ou seja, deve-se partir da sua necessidade como sujeito, da sua necessidade do novo, que emerge das contradições que o próprio educador percebe-identifica-explicita. Assim, o conflito oriundo das contradições é o motor que impulsiona a mudança de visão, o que repercute na ação do educador, promovendo uma mudança no fazer. Segundo Paulo Freire (1980), o processo de aprendizagem em si já se constitui numa forma de tomar consciência do real, não podendo, portanto, efetuar-se a não ser no seio dessa tomada de consciência.

Por sua vez, os momentos pedagógicos são utilizados para possibilitar uma prática sistemática de problematização dialógica, tanto na sala de aula 16 quanto na formação docente. Isso significa dizer que esses momentos fazem parte do processo praxiológico da formação permanente dos educadores.

A definição desses momentos pedagógicos é fruto do trabalho coletivo de quatro físicos - Marta, Angotti, Delizoicov e Cristina -, que tiveram como ponto de partida o Projeto "Ensino de Ciências, a partir dos Problemas da Comunidade" (ECPC), em São Paulo do Potengi e na Escola Estadual Jorge Fernandes.

Uma síntese (de como esses momentos se organizam) foi sistematizada na tese de doutorado de Pernambuco. Para ela, a primeira fase consiste em ouvir o outro. A segunda fase é o momento de cumprir as expectativas. A terceira fase é a síntese, quando "[...] uma fala não predomina sobre a outra, mas juntas exploram as perspectivas criadas, reforçam os instrumentos apreendidos, fazem um exercício de generalização e ampliação dos horizontes anteriormente estabelecidos" (PERNAMBUCO, 1993, p. 35-36). Esses momentos não se constituem em fases estanques e distintas no tempo, há sempre um movimento entre eles. Para a autora, é uma forma de refletir sobre aonde queremos chegar e qual direção podemos dar ao trabalho em cada momento, para 
não cair nos extremos de impor um conteúdo escolar centrado na fala de só um dos lados, do professor ou do aluno.

Desde as primeiras experiências, algumas estratégias de trabalho foram sendo sistematizadas na perspectiva de garantir a dialogicidade pretendida nas diferentes relações dos sujeitos envolvidos no processo, diálogo que é mediatizado pelo contexto de vida, ou, como diria Paulo Freire, pelo mundo. As principais sistematizações/estratégias foram:

A) A investigação temática - realizada por todos os sujeitos, inclusive alunos e a própria comunidade, com o objetivo de fazer um levantamento do contexto social, econômico, político e cultural da comunidade local, estabelecendo uma relação dialógica entre os diversos segmentos envolvidos - equipes da universidade, professores, alunos e comunidade -, mediatizada pelos dados oriundos da realidade local, que sistematizados, analisados, dão origem à programação para a sala de aula.

B) Dinâmica de trabalho com os docentes - a organização do trabalho com os professores era planejada para garantir uma relação dialógica sobre o trabaTho a ser desenvolvido com os alunos. Para Pernambuco (1988), a sequência programática a ser desenvolvida com alunos deve ser construída numa relação dialógica com os professores(as).

A dinâmica de trabalho com as professoras seguia uma sequência programática que estava organizada em tempos intensivos de longa e curta duração para a elaboração coletiva da programação e havia reuniões de acompanhamento durante todo o semestre, com um encontro final avaliativo, garantindo que todos os envolvidos no processo dialogassem em torno do objeto que os aproximava, ou seja, na perspectiva da construção coletiva da programação pedagógica.

C) Metodologia dialógica dos momentos pedagógicos -logo nas primeiras experiências - em São Paulo do Potengi e na Escola Jorge Fernandes -, a metodologia dos três momentos pedagógicos foi sistematizada para garantir a fala dos sujeitos envolvidos no processo de aprendizagem.

Para Pernambuco, esses momentos podem orientar a organização de uma aula, a sequência de conteúdos, a programação da escola, uma reunião de pais. Nesse sentido, uma fala não predomina sobre a outra, "[...] mas juntas exploram as perspectivas criadas, reforçam os instrumentos apreendidos, fazem um exercício de generalização e ampliação dos horizontes anteriormente estabelecidos" (PERNAMBUCO, 1993, p. 34). 
Os princípios identificados e discutidos acima fundamentam todas as ações educativas do GEPEM, orientando a escolha de organizadores e os parâmetros identificados nas ações formativas com professores e professoras, que, por sua vez, também são ancorados, principalmente, nas ideias de Paulo Freire.

Uma pesquisa que pretenda olhar práticas sociais educativas que se propõem a mudança, a movimento, não comporta conclusões definitivas e sim sínteses provisórias, gerando novos questionamentos e a necessidade de um novo aprofundamento. Por isso, este texto aponta apenas sínteses, pelo próprio princípio que orienta o olhar dessas práticas e do próprio GEPEM.

Ao longo do estudo, na análise das práticas formativas do GEPEM, identificamos princípios, organizadores e parâmetros. Os princípios fundamentam e orientam a escolha de organizadores, os quais são considerados fundamentais nas propostas formativas desse Grupo, aparecendo com regularidade em todas as ações analisadas neste trabalho. Desse modo, explicitamos e analisamos os princípios que fundamentam as práticas formativas do GEPEM, revelando que eles são articulados no fazer e refazer das práticas.

Atualmente, novos desafios foram impostos ao Grupo, mas é nos desa-

18 fios que encontramos força para continuar na luta por uma pedagogia do movimento alicerçada nos princípios construídos nas décadas de atuação do Grupo. A perda de Marta Pernambuco, além de repentina, nos marcou de diversas formas. Foi uma ruptura estrutural em todos os níveis que englobam a formação desse grupo. Neste momento, estamos em um processo de ruptura/ continuidade, com uma reestruturação dos sujeitos que compõem e/ou atuaram em algum momento, sintetizando e agrupando a ações coletivas para que o fluxo de formação que o GEPEM desempenha em quase 25 anos não pare. Seguimos, então, considerando a perspectiva freiriana de dialogicidade, construção coletiva a partir da ação-reflexão-ação e processo de conscientização. Ademais, seguimos também destacando o modelo adotado por Marta Pernambuco, e pelo grupo do GEPEM, de analisar práticas educativas que se propõem à mudança, promovendo a inclusão dos sujeitos de forma coletiva.

\section{Nota}

1 A professora Marta Pernambuco, apesar de sua prematura partida, consta como coautora deste artigo, considerando ser este resultado de uma tese de doutorado, tendo a referida professora 
como orientadora. Este artigo, portanto, também faz homenagem póstuma à grande pesquisadora e incentivadora do projeto dialógico, coletivo, na perspectiva freiriana.

\section{Referências}

DELIZOICOV, Demétrio. Concepção problematizadora do ensino de ciências na educação formal. 1982. Dissertação (Mestrado em Física- Programa de Pós-Graduação em Física, Universidade de São Paulo, São Paulo, 1982.

DELIZOICOV; Demétrio, CASTILHO, Nadir; CUTOLO, Luiz Roberto Agea; ROS, Marco Aurélio da; LIMA, Armênio Matias Corrêa. Sociogênese do conhecimento e pesquisa em ensino: contribuições a partir do referencial fleckiano. Caderno Brasileiro de Ensino de Física,Florianópolis, v. 19, p. 52-69, jun. 2002. (Número Especial).

DELIZOICOV, Demétrio; ANGOTTI, José André; PERNAMBUCO, Marta Maria Castanho Almeida. Ensino de ciências: fundamentos e métodos. São Paulo: Cortez, 2002.

DELIZOICOV, Demétrio. Pesquisa em Ensino de ciências como Ciências Humanas Aplicadas. Caderno Brasileiro de Ensino de Física, Florianópolis, v. 21 , n. 2, p. 145-175, ago. 2004.

FLECK, Ludwik. La génesis y el desarrollo de un hecho científico. Madrid: Alianza Editorial, 1986

FREIRE, Paulo. Conscientização: teoria e prática da libertação: uma introdução ao pensamento de Paulo Freire. São Paulo: Moraes, 1980.

FREIRE, Paulo. Pedagogia do oprimido. Rio de Janeiro: Paz e Terra, 1988.

FREIRE, Paulo. Pedagogia da esperança: um reencontro da pedagogia do oprimido. Rio de Janeiro: Paz e Terra, 1992.

FREIRE, Paulo. Pedagogia da autonomia: saberes necessários à prática educativa. 2. ed. São Paulo: Paz e Terra, 1996.

FREIRE, Paulo. Professora sim, tia não: cartas a quem ousa ensinar. São Paulo: Otho D’Água, 1998.

FREIRE, Paulo. Educação e mudança. São Paulo: Paz e Terra, 2007.

SILVA, Antonio Fernando Gouvêa da. A busca da organização curricular crítica: das falas significativas às práticas contextualizadas. São Paulo: PUC/SP, 1999. (Texto submetido ao exame de qualificação do mestrado e ascensão ao doutorado). 
SILVA, Antonio Fernando Gouvêa da. A construção do currículo na perspectiva popular crítica: das falas significativas às práticas contextualizadas. 2004. 405f. Tese (Doutorado em Educação) - Pontifícia Universidade Católica de São Paulo, São Paulo, 2004.

PERNAMBUCO, Marta Maria Castanho Almeida. Ensino de ciências a partir dos problemas da comunidade. In: CONGRESSO NORTE NORDESTE DE ENSINO DE CIÊNCIAS E MATEMÁTICA, 3, 1988, Natal. Anais [...]. Natal: Universidade Federal do Rio Grande do Norte, 1988.

PERNAMBUCO, Marta Maria Castanho Almeida. Acertando o passo. In: PONTUSCHKA, NidiaNacib (Org.). A ousadia do diálogo: interdisciplinaridade na escola. São Paulo: Loyola, 1993.

PERNAMBUCO, Marta Maria Castanho Almeida. Educação e escola com movimento: do ensino de ciências á transformação da escola pública. 1994. Tese (Doutorado em Ensino de Ciências) - Programa de Pós-Graduação Interunidades em Ensino de Ciências, Universidade de São Paulo, São Paulo, 1994.

PERNAMBUCO, Marta Maria Castanho Almeida; PAIVA, Irene. Educação e realidade Natal: SEDIS/UFRN, 2005.

20 RÊGO, Maria Carmem Freire Diógenes; PERNAMBUCO, Marta Maria Castanho Almeida. O ensino de ciências na pré-escola. In: ENCONTRO NACIONAL DE DIDÁTICA E PRÁTICA DE ENSINO, 8., 1996, Florianópolis. Anais [...]. Florianópolis: Universidade Federal de Santa Catarina, 1996.

RÊGO, Maria Carmem Freire Diógenes; PERNAMBUCO, Marta Maria Castanho Almeida. A leitura e a escrita no ensino de ciências. In: ENCONTRO DE PESQUISADORES DE ENSINO DE FÍSICA, 1996, Águas de Lindóia. Textos [...]. Águas de Lindóia, 1996a.

SEVERINO, Antonio Joaquim. Filosofia. São Paulo: Cortez, 1995.

Prof. Dra Maria Carmem Freire Diógenes Rêgo

Universidade Federal do Rio Grande do Norte (Brasil)

Núcleo de Educação da Infância (NEI)

Secretaria de Educação a Distância(SEDIS)

Grupo de Práticas Educativas em Movimento (GEPEM) 
Profa. Dra. Marta Maria Castanho Almeida Pernambuco (In Memoriam) Universidade Federal do Rio Grande do Norte (Brasil) Centro de Educação Departamento de Práticas Educacionais e Currículo Programa de Pós-Graduação em Educação Coordenadora do Grupo de Práticas Educativas em Movimento (GEPEM) Recebido 5 nov. 2018 Aceito 11 mar. 2019 